\title{
Stimulatory effect of increased non-esterified fatty acid concentrations on proinsulin processing in healthy humans
}

\author{
N.Stefan, A. Fritsche, A. Madaus, H.Häring, M. Stumvoll \\ Medical Clinic, Department of Endocrinology, Metabolism and Pathobiochemistry, Eberhard-Karls-University, Tübingen, \\ Germany
}

\section{Abstract}

Aims/hypothesis. To assess the effect of increased concentrations of non-esterified fatty acids (NEFA) on proinsulin processing in healthy humans.

Methods. We did a hyperglycaemic clamp (130 min duration, $8 \mathrm{mmol} / \mathrm{l}$ glucose, with a 5 -g arginine bolus at min 120) before and after a 5-h infusion of Intralip$\mathrm{id} /$ heparin in 14 healthy subjects. Of the subjects eight underwent a saline control experiment. The proinsulin:insulin (PI:I) ratio immediately after the arginine bolus (122.5 to $125 \mathrm{~min}$ ) was considered to provide an estimate for the conversion of proinsulin to insulin in the beta cell.

Results. Concentrations of NEFA were $757 \pm$ $86 \mu \mathrm{mol} / \mathrm{l}$ and $1669 \pm 134 \mu \mathrm{mol} / \mathrm{l}(p<0.001)$ after the 5 -h infusion of saline or Intralipid, respectively. Insulin secretion rates were no different between the Intralipid and saline infusions $(p=0.73)$. There was no statistically significant difference for either the proin- sulin concentration or the PI:I ratio during glucose stimulation alone (0 to $120 \mathrm{~min}$ ). In response to arginine, in contrast, proinsulin remained unchanged during the saline infusion (from $31 \pm 6$ to $29 \pm 7 \mathrm{pmol} / \mathrm{l}$, $p=0.50)$ but decreased during $5 \mathrm{~h}$ of lipid infusion from $(21 \pm 3$ to $15 \pm 2 \mathrm{pmol} / \mathrm{l}, p=0.02)$. The PI:I ratio in response to the arginine bolus was higher during the saline infusion $(2.0 \pm 0.2 \%$ vs $1.7 \pm 0.2 \%$, $p=0.04$ ) but decreased during the Intralipid infusion (from $1.6 \pm 0.2 \%$ to $1.2 \pm 0.1 \%, p=0.04$ ).

Conclusion/interpretation. The statistically significantly lower PI:I ratio in response to arginine during experimentally increased concentrations of NEFA suggests that NEFA increase the conversion of proinsulin to insulin in humans in vivo. [Diabetologia (2000) 43: 1368-1373]

Keywords Insulin secretion, proinsulin secretion, non-esterified fatty acids, glucose, arginine.
Increased concentrations of non-esterified fatty acid (NEFA) are believed to play a part in the pathogenesis of Type II (non-insulin-dependent) diabetes mellitus by inhibiting insulin stimulated peripheral glucose uptake and influencing beta-cell function [1-3]. The effect of NEFA on insulin secretion in vivo is a matter of debate. Although short-term high concentrations

Received: 15 March 2000 and in final revised form: 17 July 2000

Corresponding author: Dr. M. Stumvoll, Medizinische Universitätsklinik, Otfried-Müller-Str. 10, 72076 Tübingen, Germany Abbreviations: PI:I: Proinsulin to insulin; ISR: insulin secretion rate. of NEFA increased glucose-stimulated insulin secretion, prolonged higher concentrations had the opposite effect in healthy humans [4]. During a 48-h hyperglycaemic clamp, however, increased concentrations of NEFA resulted in a continuous hypersecretion of insulin [5].

The prohormone proinsulin is stored in the secretory granule of the beta cell together with insulin and $\mathrm{C}$ peptide and all three are released into the circulation during insulin secretion [6]. The relative proportion of proinsulin to insulin (PI:I) in the secretory granule represents an estimate of the efficiency of the conversion of proinsulin to insulin (proinsulin processing). A decrease in the PI:I ratio indicates an increase in the rate of proinsulin processing and vice 
versa. Also in vivo the PI:I ratio has been used to make inferences on proinsulin processing. The clearance rates of proinsulin and insulin are, however, substantially different [7]. Therefore, the PI:I ratio in plasma provides an accurate estimate for the PI:I ratio in the secretory granule only after short-term stimulation of insulin secretion [8-11] when differences in elimination kinetics are negligible for concentrations.

An increased PI:I ratio has been observed in conditions with impaired beta-cell function such as Type II diabetes [12-14] and impaired glucose tolerance $[11,15]$. The disproportionate increase of proinsulin compared with insulin is thought to reflect an ineffective processing of proinsulin to insulin in the beta cell. Because NEFA concentrations are frequently increased in patients with Type II diabetes and impaired glucose tolerance it is possible that NEFA are involved in the beta-cell dysfunction characteristic of these conditions. In vitro studies showed that 48 -h incubation with palmitate resulted in an increase in the PI:I ratio in response to glucose stimulation [16]. This was interpreted as an inhibitory effect of NEFA on proinsulin conversion to insulin. It is not known, however, how increased NEFA concentrations influence proinsulin processing in humans in vivo.

The purpose of our study was to examine the effect of increased concentrations of NEFA on the PI:I ratio in response to short-term stimuli in healthy humans. We therefore analysed the plasma PI:I ratios in response to glucose (bolus, 2-h square-wave hyperglycaemia, $\sim 8 \mathrm{mmol} / \mathrm{l}$ ) and to a 5-g arginine bolus done before and during a 5-h infusion with Intralipid/heparin in 14 healthy volunteers. A saline control experiment was done in eight healthy subjects.

\section{Subjects and methods}

Subjects. We studied healthy, normal-glucose-tolerant volunteers of German origin. Subjects, $n=14$ underwent the Intralipid/heparin experiment and 8 , matched with them for age, sex and BMI underwent the saline control experiment (Table 1). The study protocol was approved by the ethics committee of the University of Tübingen. Before the study, informed written consent was obtained from all participants.

Experimental design. In both experiments a baseline hyperglycaemic clamp (130-min duration plus an arginine bolus at $120 \mathrm{~min}$ ) was done at around 0700 hours after an overnight fast. Immediately after completion of the baseline clamp an infusion of either normal saline or Intralipid 20\% (Pharmacia \& Upjohn, Erlangen, Germany) $\left(0.83 \mathrm{ml} \cdot \mathrm{kg}^{-1} \cdot \mathrm{h}^{-1}\right)$ plus heparin ( $800 \mathrm{U} / \mathrm{h}$, priming dose $1000 \mathrm{U}$ ) was started. The Intralipid was taken from a single batch and the fatty acid composition was as follows: $13 \%$ palmitate $(16: 0), 4 \%$ stearate $(18: 0), 22 \%$ oleate (18:1), $52 \%$ linoleic acid (18:2 $\omega 6), 8 \%$ linolenic acid $(18: 3 \omega 3)$ and $1 \%$ others (information provided by Pharmacia \& Upjohn, product management). After $5 \mathrm{~h}$ a second hyperglycaemic clamp was done analogously while the Intralipid or saline infusions were continued.
Clamp protocol. A hand vein was cannulated retrogradly and kept in a thermoregulated box at $55^{\circ} \mathrm{C}$ to obtain arterialized blood samples. At the same time, an antecubital vein was cannulated for infusions. After baseline samples had been obtained an intravenous bolus of $20 \%$ glucose over 1 min was given to instantaneously raise blood glucose to $10 \mathrm{mmol} / \mathrm{l}$. The bolus dose was individually calculated to achieve similar glucose peaks using the following formula: bolus dose $(\mathrm{mg})=$ body weight $(\mathrm{kg}) \times$ desired increase in blood glucose $(\mathrm{mg} / \mathrm{dl}) \times 1.5$. Subsequently, a glucose infusion was adjusted to maintain blood glucose at $8 \mathrm{mmol} / \mathrm{l}$. After $120 \mathrm{~min}$ a bolus of $5 \mathrm{~g}$ arginine hydrochloride (Pharmacia \& Upjohn) was injected over $45 \mathrm{~s}$.

Plasma glucose was measured bedside with a HemoCue blood glucose photometer (HemoCue AB, Aengelholm, Sweden) at 5-min intervals. Samples for insulin (microparticle enzyme immunoassay, Abbott Laboratories, Tokyo, Japan, CV 2.5-6\%), C peptide (Byk-Sangtec, Dietzenbach, Germany) and proinsulin (enzyme immunoassay, IBL, Hamburg, Germany) measurement were taken at $-15,-5,0,2.5,5,7.5,10,80,100$, $120,122.5125,127.5$ and 130 min during the clamp. According to the manufacturer's information the proinsulin assay has zero $\%$ cross reactivity with human insulin and $\mathrm{C}$ peptide. Samples for measurement of non-esterified fatty acids (enzymatic method, NEFAC kit, WACO Chemicals, Neuss, Germany) were taken at $-15,-5,60,120,240,360,415,430,490$ and $550 \mathrm{~min}$.

Determination of insulin secretion rate (ISR). Standard kinetic parameters for C-peptide (rate constants, volume of distribution) adjusted for age, sex, BMI and body surface area were used [17] and assumed to remain unchanged throughout the experiment. These parameters were used to calculate the ISR for the indicated intervals from the plasma C-peptide concentrations by deconvolution as described previously [18].

Calculations and statistical analysis. Unless otherwise stated data are given as means \pm SEM. First-phase insulin secretion was calculated as the mean of the 2.5 and 5 min value, secondphase as the mean of the 80,100 and 120 min value and the response to arginine as the mean of the 122.5 and 125 min values. Statistical comparisons between the basal and 5-h clamp within the saline or Intralipid protocol was done using the paired student's $t$ test (two-tailed). For comparison between the saline or Intralipid protocol an unpaired student's $t$ test (two-tailed) was done on the differences (value of the 5-h clamp minus value of the basal clamp). A $p$ value of less than 0.05 was considered to be statistically significant.

\section{Results}

Non-esterified fatty acids. The concentrations of NEFA increased from around $100 \mu \mathrm{mol} / \mathrm{l}$ by the end of the basal clamp to $757 \pm 86$ (saline protocol) and $1669 \pm 134 \mu \mathrm{mol} / \mathrm{l}$ (Intralipid protocol) before the second clamp $(p<0.001)$ (Fig. 1).

Insulin secretion rates and serum insulin concentrations. Insulin secretion rates and insulin concentrations are shown in figures 2 and 3 . In both the saline and the Intralipid experiment the basal and 5-h curves were essentially superimposable. There was no statistical difference for any of the ISR phases. Whereas the insulin concentrations in response to 


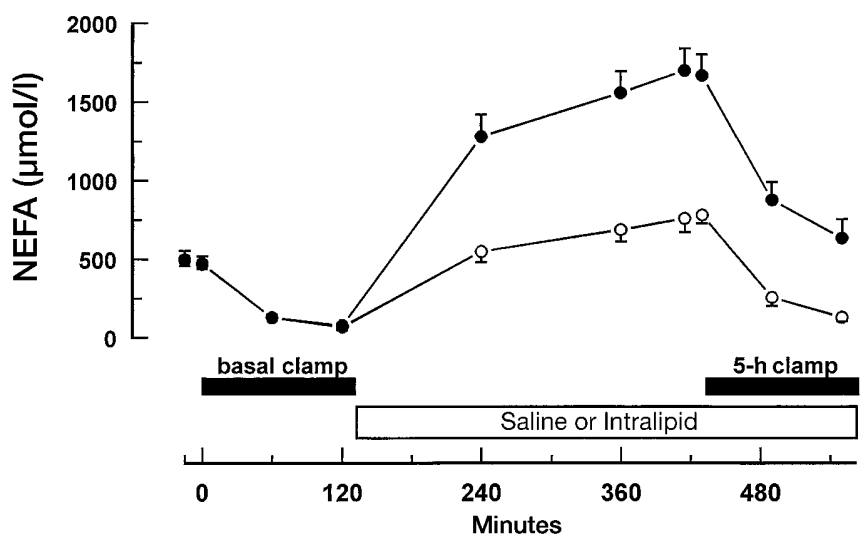

Fig. 1. Serum NEFA concentrations during the basal clamp and during the clamp after 5-hour infusion of saline $(\bigcirc)$ or Intralipid (O)

Table 1. Subjects characteristics

\begin{tabular}{lccl}
\hline & $\begin{array}{l}\text { Control } \\
\text { group } \\
\text { (Saline) }\end{array}$ & $\begin{array}{l}\text { Experimental } \\
\text { group } \\
\text { (Intralipid) }\end{array}$ & $p$ \\
\hline$n($ male/female) & $6 / 2$ & $10 / 4$ & $0.11^{\mathrm{b}}$ \\
Age $(\mathrm{year})^{\mathrm{a}}$ & $31 \pm 5$ & $32 \pm 7$ & 0.51 \\
$\mathrm{BMI}\left(\mathrm{kg} / \mathrm{m}^{2}\right)^{\mathrm{a}}$ & $22.4 \pm 1.9$ & $23.1 \pm 2.0$ & 0.49 \\
Body weight $(\mathrm{kg})^{\mathrm{a}}$ & $70 \pm 7$ & $70 \pm 9$ & 0.76 \\
Fasting insulin $(\mathrm{pmol} / \mathrm{l})$ & $39 \pm 7$ & $31 \pm 3$ & 0.38 \\
Fasting glucose $(\mathrm{mmol} / \mathrm{l})$ & $85 \pm 3$ & $84 \pm 2$ & 0.78 \\
\hline
\end{tabular}

${ }^{\mathrm{a}}$ means $\pm \mathrm{SD},{ }^{\mathrm{b}}$ by Chi-squared test

arginine during the saline infusion decreased significantly, they remained, however, unchanged during Intralipid infusion (Table 2). The difference of the change nevertheless, was not significantly different between the experiments $(p=0.31)$.

Serum proinsulin concentrations. Proinsulin increased from about $8 \pm 2 \mathrm{pmol} / \mathrm{l}$ before the clamp to a maximum of around $30 \pm 7 \mathrm{pmol} / \mathrm{l}$ at $122.5 \mathrm{~min}$ (Fig. 2). There was no significant difference between the basal and the 5-h clamp for the 0 to 120 min interval in either protocol. In response to arginine, proinsulin decreased, however, significantly from $21 \pm 3$ basally to $15 \pm 2 \mathrm{pmol} / \mathrm{l}$ after 5 -h infusion of Intralipid ( $p=0.02$ ) but remained unchanged during the saline infusion $(31 \pm 6$ vs $29 \pm 7 \mathrm{pmol} / \mathrm{l}, p=0.50)$.

Proinsulin:insulin (PI:I) ratios. The PI:I ratio was $17 \%$ before the basal clamp (Fig. 4). During the hyperglycaemic clamp the PI:I ratio decreased sharply in response to the glucose bolus reaching a minimum of about $2.5 \%$ at $2.5 \mathrm{~min}$ in both protocols. It subsequently plateaued at around $9 \%$ and after the arginine bolus decreased to a trough value of approximately $1 \%$.

The PI:I ratio for first phase (2.5 to $5 \mathrm{~min}$ ) did not change during the saline infusion (from $3.7 \pm 1.2 \%$
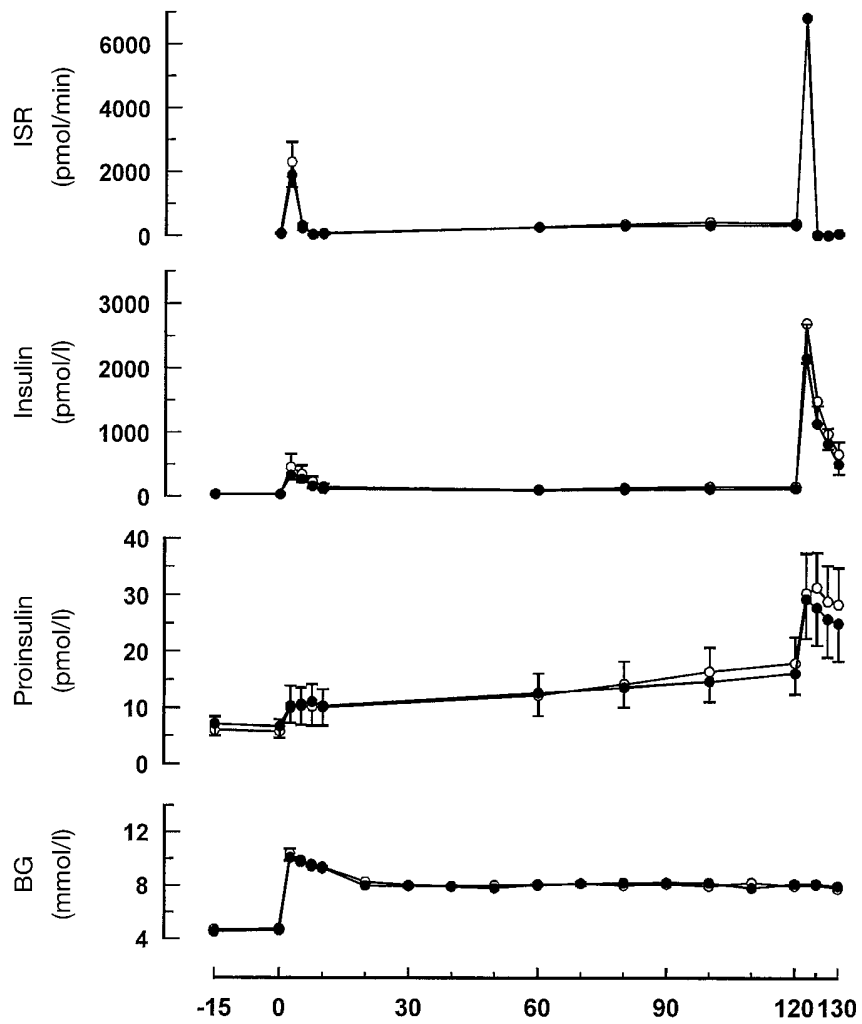

Fig. 2 A-D. Insulin secretion rate (ISR) (A), serum insulin (B) and proinsulin $(\mathbf{C})$ concentrations, blood glucose (BG) (D) during the basal clamp and during the clamp after 5 -h infusion of saline. $\bigcirc$ Basal, $5 \mathrm{~h}$

to $3.2 \pm 0.6 \%, p=0.65)$ or the Intralipid infusion (from $3.3 \pm 0.9 \%$ to $3.1 \pm 0.4 \%, p=0.76$ ). Similarly, the PI:I ratio for second phase (80 to $120 \mathrm{~min}$ ) did not change during the saline infusion (from $10.4 \pm 1.7 \%$ to $11.6 \pm 1.3 \%, p=0.26$ ) or the Intralipid infusion (from $7.6 \pm 1 \%$ to $7.5 \pm 1.1 \%, p=0.89$ ). In contrast, the PI:I ratio in response to the arginine bolus tended to be higher during the saline infusion $(2.0 \pm 0.2 \%$ vs $1.7 \pm 0.2 \%, p=0.04)$ and decreased significantly during the Intralipid infusion (from $1.6 \pm 0.2 \%$ to $1.2 \pm 0.1 \%, p=0.04)$. The change was also significantly different between the two experiments $(p=0.02)$ (Table 2). Figure 5 shows the individual data for the PI:I ratio before and after saline and Intralipid infusion, respectively.

\section{Discussion}

In this study the influence of experimentally increased concentrations of non-esterified fatty acids on proinsulin secretion and the PI:I ratio as estimate for the conversion of proinsulin to insulin was investigated in normal subjects. Compared with the saline experiment there was no difference in either proinsulin secretion or the PI:I ratio during moderate stimulation of insulin secretion by the initial glucose bolus 

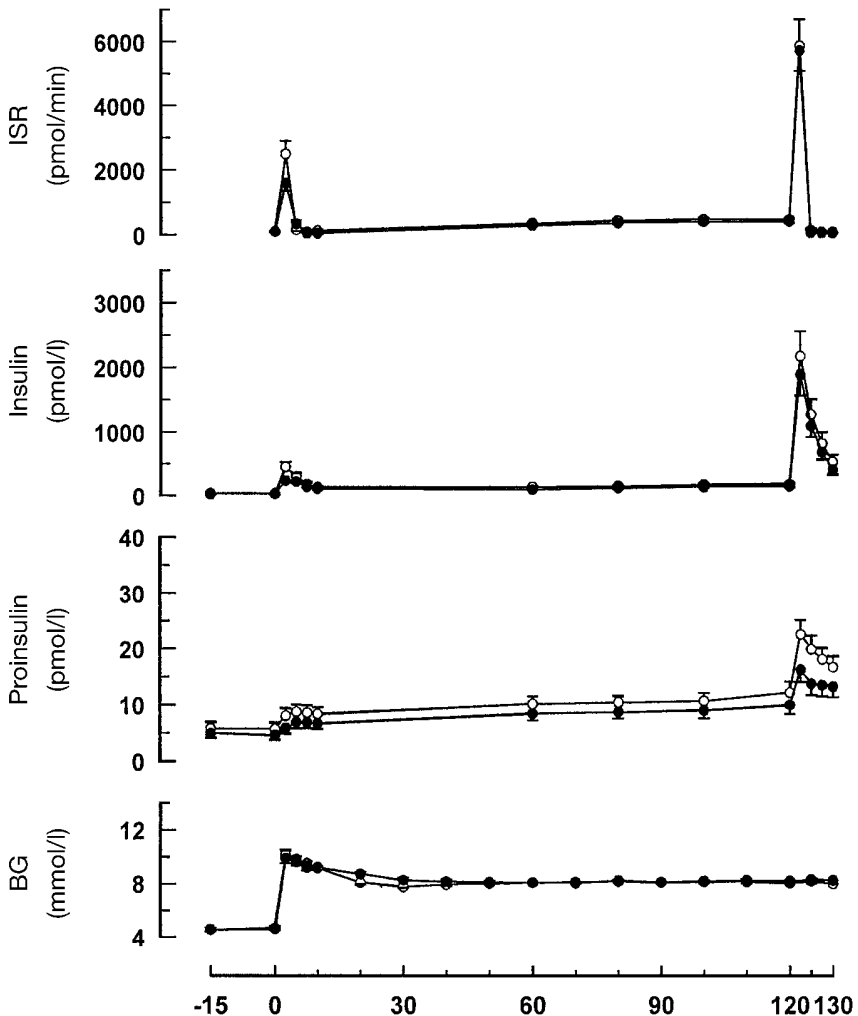

Fig. 3 A-D. Insulin secretion rate (ISR) (A), serum insulin (B) and proinsulin $(\mathbf{C})$ concentrations, blood glucose (BG) (D) during the basal clamp and during the clamp after 5-h infusion of Intralipid. $\bigcirc$ Basal, $5 \mathrm{~h}$

or $2 \mathrm{~h}$ of hyperglycaemia. Furthermore, 5-h increase of non-esterified fatty acid concentration had no statistically significant effect on insulin secretion. After short-term stimulation of insulin secretion by the potent secretagogue arginine circulating proinsulin concentrations were, however, significantly lower after concentrations of NEFA were increased compared with the saline control experiment. This resulted in a statistically significantly lower PI:I ratio during the 5-h lipid infusion.

The effect could seem small in absolute terms but in 11 out of 14 subjects the PI:I ratio after the arginine bolus decreased during the lipid while it increased during the saline infusion. The marginal increase of the PI:I ratio during the saline experiment could indicate some exhaustion of insulin synthesis as a consequence of the preceding (i.e. baseline) hyperglycaemic clamp including the arginine bolus. Thus, increased concentrations of NEFA could not only have prevented this exhaustion but even resulted in an increase of proinsulin conversion to insulin.

Our findings are in clear contrast to the findings of a previous study [16] in which incubation of isolated human beta cells with $0.2 \mathrm{mmol} / \mathrm{l}$ palmitate for $48 \mathrm{~h}$ resulted in an increased secretion of proinsulin and a higher PI:I ratio after stimulation with $27 \mathrm{mmol} / \mathrm{l} \mathrm{glu}$ cose. This was interpreted by the authors as an inhib-
Table 2. Insulin secretion rates (ISR), serum insulin concentrations, serum proinsulin concentrations and proinsulin:insulin ratios (PI:I) during the short-term arginine stimulation (mean of 122.5 and $125 \mathrm{~min}$ )

\begin{tabular}{lllll}
\hline & & Saline & Intralipid & $p$ \\
\hline ISR & basal & $3620 \pm 526$ & $2989 \pm 404$ & \\
$\left(\mathrm{pmol} \times \mathrm{min}^{-1}\right)$ & $5 \mathrm{~h}$ & $3441 \pm 625$ & $2882 \pm 319$ & \\
& difference & $-179 \pm 207$ & $-106 \pm 217$ & 0.82 \\
& $p$ & 0.35 & 0.63 & \\
Insulin & basal & $2099 \pm 448$ & $1724 \pm 306$ & \\
$(\mathrm{pmol} / \mathrm{l})$ & $5 \mathrm{~h}$ & $1654 \pm 405$ & $1493 \pm 245$ & \\
& difference & $-445 \pm 138$ & $-230 \pm 125$ & 0.31 \\
& $p$ & 0.02 & 0.10 & \\
Proinsulin & basal & $31 \pm 6$ & $21 \pm 3$ & \\
$($ pmol/l) & $5 \mathrm{~h}$ & $29 \pm 7$ & $15 \pm 2$ & \\
& difference & $-2 \pm 3$ & $-6 \pm 2$ & 0.2 \\
& $p$ & 0.50 & 0.02 & \\
PI:I & basal & $1.7 \pm 0.2$ & $1.6 \pm 0.2$ & \\
$(\%)$ & $5 \mathrm{~h}$ & $2.0 \pm 0.2$ & $1.2 \pm 0.1$ & \\
& difference & $0.2 \pm 0.1$ & $-0.4 \pm 0.2$ & 0.02 \\
& $p$ & 0.04 & 0.04 & \\
\hline
\end{tabular}

$\overline{\text { Data are shown as means } \pm \text { SEM basally and after } 5 \mathrm{~h} \text { of saline }}$ or Intralipid infusion

itory effect of NEFA on proinsulin secretion. Our findings are also at variance with in vitro data showing a delayed processing of proinsulin after 7-day incubation with a NEFA mixture (palmitate:oleate $=1: 2$ ) [19]. One possible explanation for this discrepancy could be the fatty acid composition of the increased concentrations of plasma NEFA during infusion of Intralipid. The emulsion we used contained mostly linoleate, less oleate and palmitate (approximately 5:2:1.5). The chain length of fatty acids has been shown to affect insulin secretion in the perfused rat pancreas [20] and in perifused mouse islets [21]. The saturation of the fatty acids has been shown to influence insulin secretion [20] and preproinsulin gene expression [22]. Moreover, spatial configuration (cis vs trans fatty acids) has been shown to modulate glucose oxidation and insulin secretion in isolated mouse islets [23]. It is thus possible, that chain length and the degree of saturation of the fatty acid have an effect also on proinsulin processing. Our lipid emulsion contained a high proportion of linoleate $(18: 2 \omega 6)$ and relatively little palmitate (16:0) whereas in the previous study [16] palmitate was used which might explain this apparent discrepancy. It is therefore important to realize differences in experimental design between in vitro and in vivo studies. Whereas the former permit investigation of individual fatty acids, the latter can only provide a net effect of several fatty acids.

It has been found, however, that 24-h incubation of beta cells with oleate increase insulin secretion, decrease intracellular insulin stores but does not alter proinsulin mRNA expression. This was interpreted as insulin biosynthesis, which includes the processing 

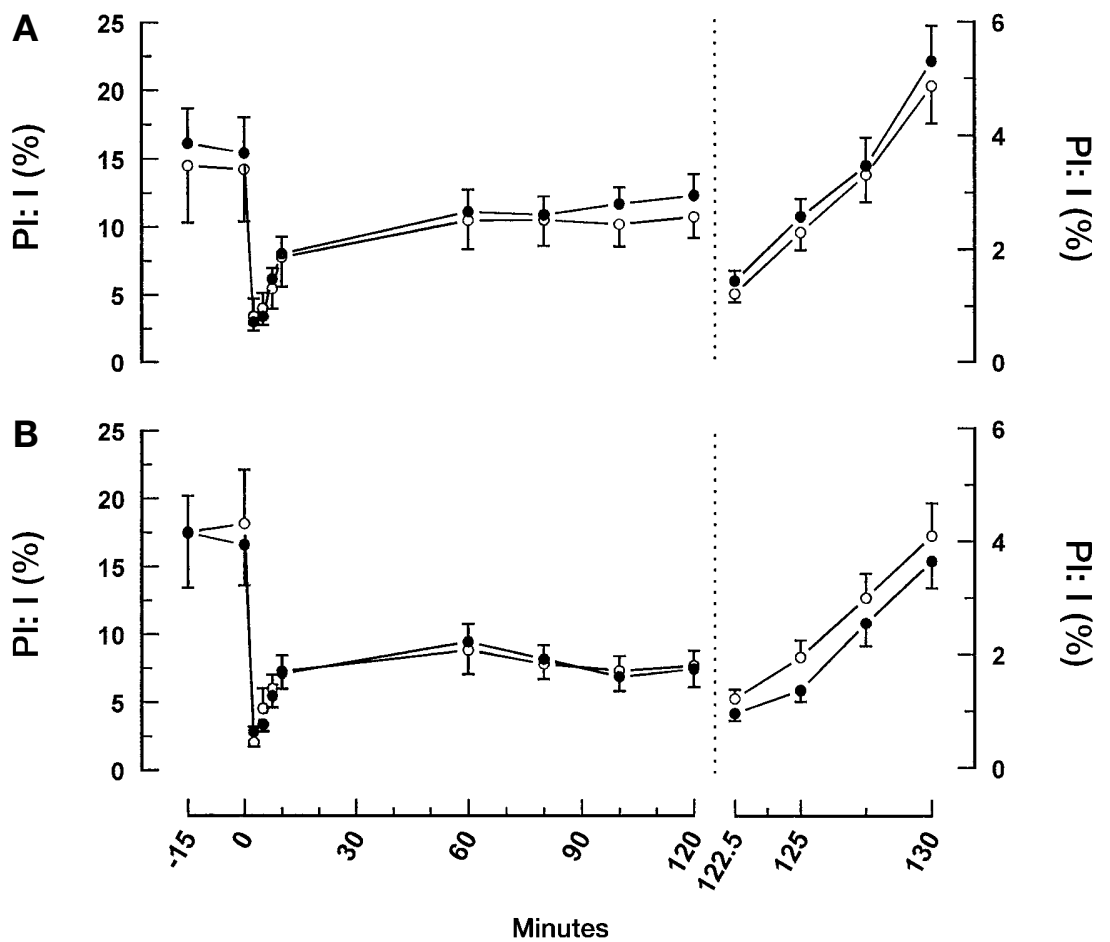

Fig.4A,B. Plasma proinsulin:insulin ratio during the basal clamp and during the clamp after $5 \mathrm{~h}$ infusion of saline $(\mathbf{A})$ or Intralipid (B). OBasal, $\bigcirc \mathrm{h}$
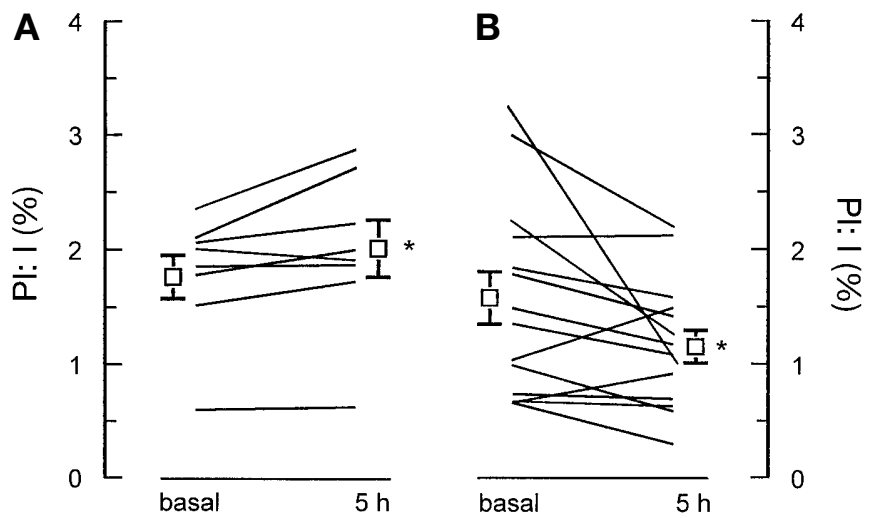

Fig. 5 A,B. Individual plasma proinsulin:insulin ratios immediately after short-term stimulation of insulin secretion with arginine before and after 5-h infusion of saline (A) or Intralipid (B). $(*$, both $p=0.04)$

of proinsulin, not being able to compensate for the NEFA-induced hypersecretion [24]. Although the conversion of proinsulin to insulin was not assessed directly the data suggested that oleate stimulated proinsulin processing at least to some extent.

A potential mechanism underlying our observations could involve the nervous system. Not only insulin secretion but also the biosysnthesis of insulin has been shown to be under neuronal control [25].
Recent findings in rats indicated that lipid infusion resulted in lower sympathetic nervous activity which provoked hyperresponsiveness of the beta cell to glucose [26]. It is thus possible that neuronal signals mediated the NEFA effect on proinsulin processing.

The results of our study showed that in humans experimentally increasing NEFA concentrations increased the conversion of proinsulin to insulin. This contrasted with findings in vitro. Our results suggest that increased concentrations of NEFA which is characteristic of Type II diabetes is unlikely to contribute to the hyperproinsulinaemia seen in this condition.

Acknowledgements. We thank all the research volunteers for their participation. We gratefully acknowledge the excellent technical assistance of U. Schmidt, A. Teigeler and S. Obermüller. This study was supported by a fortüne grant (project \# 1284100) to Drs. Fritsche and Stumvoll. We are also indebted to A. Wochner, a medical student, who helped with many experiments.

\section{References}

1. Boden G (1997) Role of fatty acids in the pathogenesis of insulin resistance and NIDDM. Diabetes 46: 3-10

2. McGarry JD, Dobbins RL (1999) Fatty acids, lipotoxicity and insulin secretion. Diabetologia 42: 128-138

3. Paolisso G, Howard BV (1998) Role of non-esterified fatty acids in the pathogenesis of type 2 diabetes. Diabetic Med 15: 360-366

4. Paolisso G, Gambardella A, Amato L et al. (1995) Opposite effects of short- and long-term fatty acid infusion on insulin secretion in healthy subjects. Diabetologia 38: 1295-1299 
5. Boden G, Chen X, Rosner J, Barton M (1995) Effects of a 48-h fat infusion on insulin secretion and glucose utilization. Diabetes 44: 1239-1242

6. Rhodes CJ, Alarcon C (1994) What beta-cell defect could lead to hyperproinsulinemia in NIDDM? Some clues from recent advances made in understanding the proinsulin-processing mechanism. Diabetes 43: 511-517

7. Starr JI, Rubenstein AH (1974) Metabolism of endogenous proinsulin and insulin in man. J Clin Endocrinol Metab 38: 305-308

8. Kahn SE, McCulloch DK, Schwartz MW, Palmer JP, Porte D, Jr. (1992) Effect of insulin resistance and hyperglycaemia on proinsulin release in a primate model of diabetes mellitus. J Clin Endocrinol Metab 74: 192-197

9. Ward WK, LaCava EC, Paquette TL, Beard JC, Wallum BJ, Porte D, Jr. (1987) Disproportionate elevation of immunoreactive proinsulin in Type II (non-insulin-dependent) diabetes mellitus and in experimental insulin resistance. Diabetologia 30: 698-702

10. Ward WK, Paquette TL, Frank BH, Porte D Jr (1986) A sensitive radioimmunoassay for human proinsulin, with sequential use of antisera to C-peptide and insulin. Clin Chem 32: 728-733

11. Larsson H, Ahren B (1999) Relative hyperproinsulinemia as a sign of islet dysfunction in women with impaired glucose tolerance. J Clin Endocrinol Metab 84: 2068-2074

12. Ward WK, LaCava EC, Paquette TL, Beard JC, Wallum BJ, Porte D, Jr. (1987) Disproportionate elevation of immunoreactive proinsulin in Type II (non-insulin-dependent) diabetes mellitus and in experimental insulin resistance. Diabetologia 30: 698-702

13. Roder ME, Porte D, Jr., Schwartz RS, Kahn SE (1998) Disproportionately elevated proinsulin levels reflect the degree of impaired B cell secretory capacity in patients with noninsulin-dependent diabetes mellitus. J Clin Endocrinol Metab 83: 604-608

14. Saad MF, Kahn SE, Nelson RG et al. (1990) Disproportionately elevated proinsulin in Pima Indians with noninsulin-dependent diabetes mellitus. J Clin Endocrinol Metab 70: $1247-1253$

15. Krentz AJ, Clark PM, Cox L, Nattrass M (1993) Hyperproinsulinaemia in impaired glucose tolerance. Clin Sci (Colch) 85: 97-100

16. Björklund A, Grill V (1999) Enhancing effects of longterm elevated glucose and palmitate on stored and secreted proinsulin-to-insulin ratios in human pancreatic islets. Diabetes 48: 1409-1414

17. Van Cauter E, Mestrez F, Sturis J, Polonsky KS (1992) Estimation of insulin secretion rates from C-peptide levels. Comparison of individual and standard kinetic parameters for C-peptide clearance. Diabetes 41: 368-377

18. Eaton RP, Allen RC, Schade DS, Erickson KM, Standefer J (1980) Prehepatic insulin production in man: kinetic analysis using peripheral connecting peptide behavior. J Clin Endocrinol Metab 51: 520-528

19. Furukawa H, Carroll RJ, Swift HH, Steiner DF (1999) Long-term elevation of free fatty acids leads to delayed processing of proinsulin and prohormone convertases 2 and 3 in the pancreatic beta-cell line MIN6. Diabetes 48: 1395-1401

20. Stein DT, Stevenson BE, Chester MW et al. (1997) The insulinotropic potency of fatty acids is influenced profoundly by their chain length and degree of saturation. J Clin Invest 100: 398-403

21. Opara EC, Garfinkel M, Hubbard VS, Burch WM, Akwari OE (1994) Effect of fatty acids on insulin release: role of chain length and degree of unsaturation. Am J Physiol 266: E635-E639

22. Ritz Laser B, Meda P, Constant I et al. (1999) Glucose-induced preproinsulin gene expression is inhibited by the free fatty acid palmitate. Endocrinology 140: 4005-4014

23. Alstrup KK, Gregersen S, Jensen HM, Thomsen JL, Hermansen K (1999) Differential effects of cis and trans fatty acids on insulin release from isolated mouse islets. Metabolism 48: 22-29

24. Bollheimer LC, Skelly RH, Chester MW, McGarry JD, Rhodes CJ (1998) Chronic exposure to free fatty acids reduces pancreatic beta cell insulin content by increasing basal insulin secretion that is not compensated for by a corresponding increase in proinsulin biosynthesis translation. J Clin Invest 101: 1094-1101

25. Ahren B, Taborsky GJ Jr, Porte D Jr (1986) Neuropeptidergic versus cholinergic and adrenergic regulation of islet hormone secretion. Diabetologia 29: 827-836

26. Magnan C, Collins S, Berthault MF et al. (1999) Lipid infusion lowers sympathetic nervous activity and leads to increased beta-cell responsiveness to glucose. J Clin Invest 103: 413-419 